\title{
AN ALTERNATIVE TECHNIQUE FOR BRONCHIAL ASPIRATION THROUGH A TRACHEOSTOMY
}

\author{
By D. J. E. Cheshire, M.B., B.S., D.Phys.Med., and K. M. Foster, M.B., B.S.* \\ Spinal Injuries Centre, Austin Hospital, Heidelberg, Victoria, Australia
}

THE commonest cause of death in Acute Traumatic Tetraplegia is respiratory failure due to the supervention of pulmonary consolidation or collapse. A régime of respiratory management was described in a previous paper (Cheshire, I964) and emphasis was laid on the necessity for the timely use of tracheostomy for the aspiration of copious pulmonary secretions, and on the value of bronchoscopy through the stoma, with aspiration of secretions under direct vision. Attempts to aspirate both bronchi with a Tiemann's catheter introduced through the tracheostomy tube have proved to be unreliable and have not prevented major bronchial obstruction from occurring. The technique of turning the head to guide the catheter into the opposite bronchus is not applicable to the tetraplegic patient with a fracture or dislocation of the cervical spine.

With further experience, a technique has been developed which permits bronchial aspiration in a manner less disturbing to the patient and which has the advantage that it may be performed as frequently as necessary by any doctor familiar with the technique. The technique uses Magill's endotracheal tubes which are adapted to serve as guides for the passage of a soft rubber catheter into either main bronchus. Although the procedure is not performed under direct vision, the usage of the modified Magill's tubes permits almost certain entry into the desired main bronchus.

\section{EQUIPMENT}

(a) The Endotracheal Tubes. Two size 8 Magill's endotracheal tubes are used. The tubes are cut distally to make, in one, an oblique opening facing to the right, and, in the other, an oblique opening facing to the left. Proximally the tubes are cut transversely to permit projection of about $3 \mathrm{~cm}$. from the tracheostomy stoma when the distal end is at the level of the carina.

Cuffed tubes are used to prevent the inhalation of vomitus and to assist in the adequate ventilation of the apnoeic patient at intervals during the procedure.

An alternative to the Magill's tube is to use a soft rubber armoured straight endotracheal tube, cut proximally to the same length as the Magill's tubes. The tube, which is indelibly marked at its proximal end to indicate the direction of its distal opening, is introduced with a curved metal introducer. After aspiration of one bronchus the tube is withdrawn slightly, rotated through $180^{\circ}$, replaced, and is then in the correct position for the aspiration of the other bronchus.

(b) The Suction Catheters. No. I2 F.G. soft rubber catheters with a single terminal oblique opening are used to apply suction directly along the length of the bronchus. Catheters with side openings are not used as they tend to adhere to the bronchial mucosa. Furthermore, a lateral dissipation of the suction force reduces efficacy.

\footnotetext{
* Present Address: Alfred Hospital, Melbourne.
} 


\section{METHOD}

The procedure is performed with the patient in the supine position as often as necessary, preferably as soon as possible after secretions have been drained into the main bronchi by the use of posture and coughing under the supervision of the chest physiotherapist. The operator, who is fully scrubbed and wearing mask, gown and gloves, stands at the right side of the bed. A nurse stands at the left side of the bed ready to assist by performing oro-pharyngeal suction when necessary.

The tracheostomy tube and flange are removed to expose the stoma, and sterile drapes are arranged. The trachea is aspirated with a soft rubber catheter. A lightly lubricated modified endotracheal tube, as described above, is then passed gently through the stoma until the carina is reached; this is judged by a feeling of resistance to further passage and the patient may cough. The tube is withdrawn slightly and a catheter moistened with sodium bicarbonate solution is passed down the endotracheal tube to protrude just beyond the tip. With the endotracheal tube cut, as described, the catheter is accurately guided into whichever bronchus is desired. The soft rubber catheter is occluded by pinching with the finger during its downward passage.

The occlusion is then released and the catheter withdrawn gently, with rotation between thumb and index finger. After withdrawal the sodium bicarbonate solution is sucked through the catheter to clean it, and repeated aspirations are performed, each time gently advancing the tip of the catheter further down the bronchus until it reaches about $5 \mathrm{~cm}$. beyond the tip of the endotracheal tube.

If the endotracheal tube should become blocked by tenacious sputum adhering to the catheter, the tube and catheter are withdrawn together, and after cleansing the tube may be reinserted and further aspirations performed.

When the aspiration of one main bronchus is finished, the endotracheal tube is removed, and another tube with a distal opening facing in the opposite direction is inserted (fig. I). Separate catheters are used for the aspiration of each bronchus, and for the trachea. After the aspiration is finished, a fresh James' tracheostomy tube is inserted.

If the patient is suffering from respiratory insufficiency it may be necessary to interrupt the procedure for periods of assisted respiration.

\section{ILLUSTRATIVE CASE History}

Following a water-skiing accident, a 69-year-old man was admitted with a fracture of the odontoid process, posterior dislocation of the atlas on the axis and an incomplete cervical spinal cord lesion. During the last 50 miles of the 150-mile ambulance journey he became apnoeic and lost consciousness. He was given artificial respiration through a face mask.

On admission, nine hours after the accident, he was cyanosed, deeply unconscious and areflexic. Tracheostomy was performed and intermittent positive pressure respiration commenced. Crutchfield tongs and skeletal traction werapplied to the skull. Within one hour of admission the patient regained consciouse ness, and in a further four hours there was a return of power in all muscles of the lower limbs to power 3 (M.R.C. Scale). Total intercostal paralysis persisted, but there was return of feeble diaphragmatic function-Tidal Volume $65 \mathrm{ml}$., but rapidly fatiguing. By the end of the 2nd day there was a sustained Tidal Volume of $80 \mathrm{ml}$., and by the 5 th day $200 \mathrm{ml}$. 
On the 7 th day the patient developed a collapse of the right lower lobe. Bronchoscopy through the tracheostomy stoma with aspiration of secretions was followed by partial re-expansion. On the 8th day there was collapse of the left lower lobe; bronchoscopy was repeated, and thick mucopurulent secretion aspirated from the left lower lobe bronchus. The lobe was re-expanded. On the I Ith day collapse of the left lower lobe recurred. The method of aspiration described in this paper was used, much tenacious secretion was removed, and complete re-expansion of the left lower lobe was demonstrated (figs. 2 and 3 ). The technique was used two or three times a day as repeated areas of partial collapse occurred in both lower lobes.

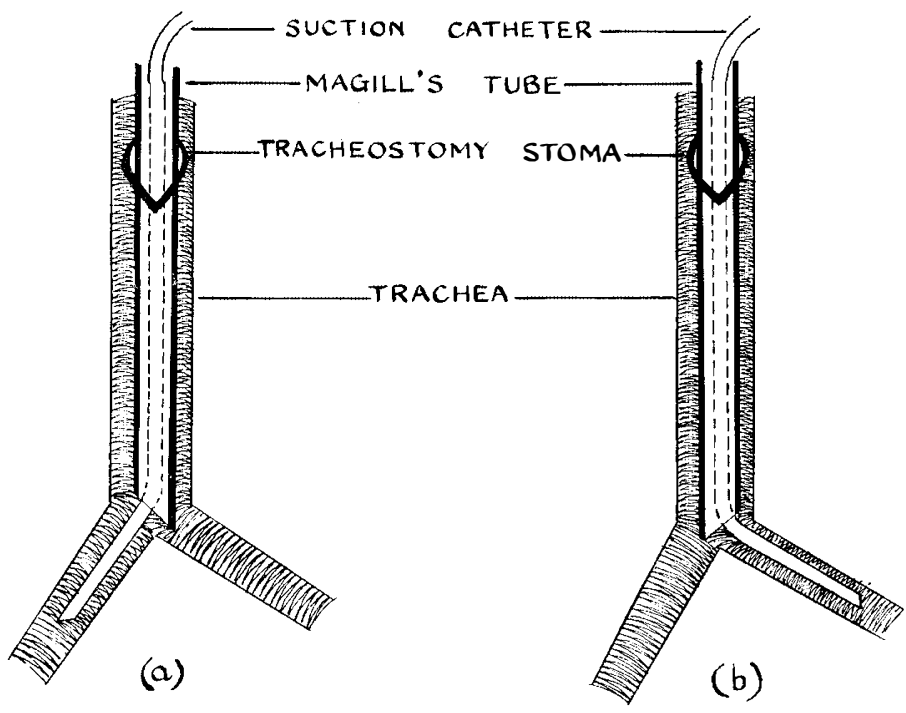

FIG. I

Bronchial Aspiration.

(a) Aspiration of the right bronchus. (b) Aspiration of the left bronchus.

The chest was clear by the I 5 th day, and the tracheostomy tube was removed on the I th day. The chest remains clear, and the patient is making a progressive neurological recovery.

\section{DISCUSSION}

This method for the bronchial aspiration of a patient with a tracheostomy is presented because it is felt that it is safe, efficient, and can be performed, if necessary, several times daily by the Resident Medical Officer. The method is particularly applicable in the management of an acute tetraplegic patient because in these patients with skull traction, bronchoscopy from the head end of the bed can be technically difficult. This method, which is performed from the side of the bed, is much more convenient, and there is no need whatever for movement of the head or 


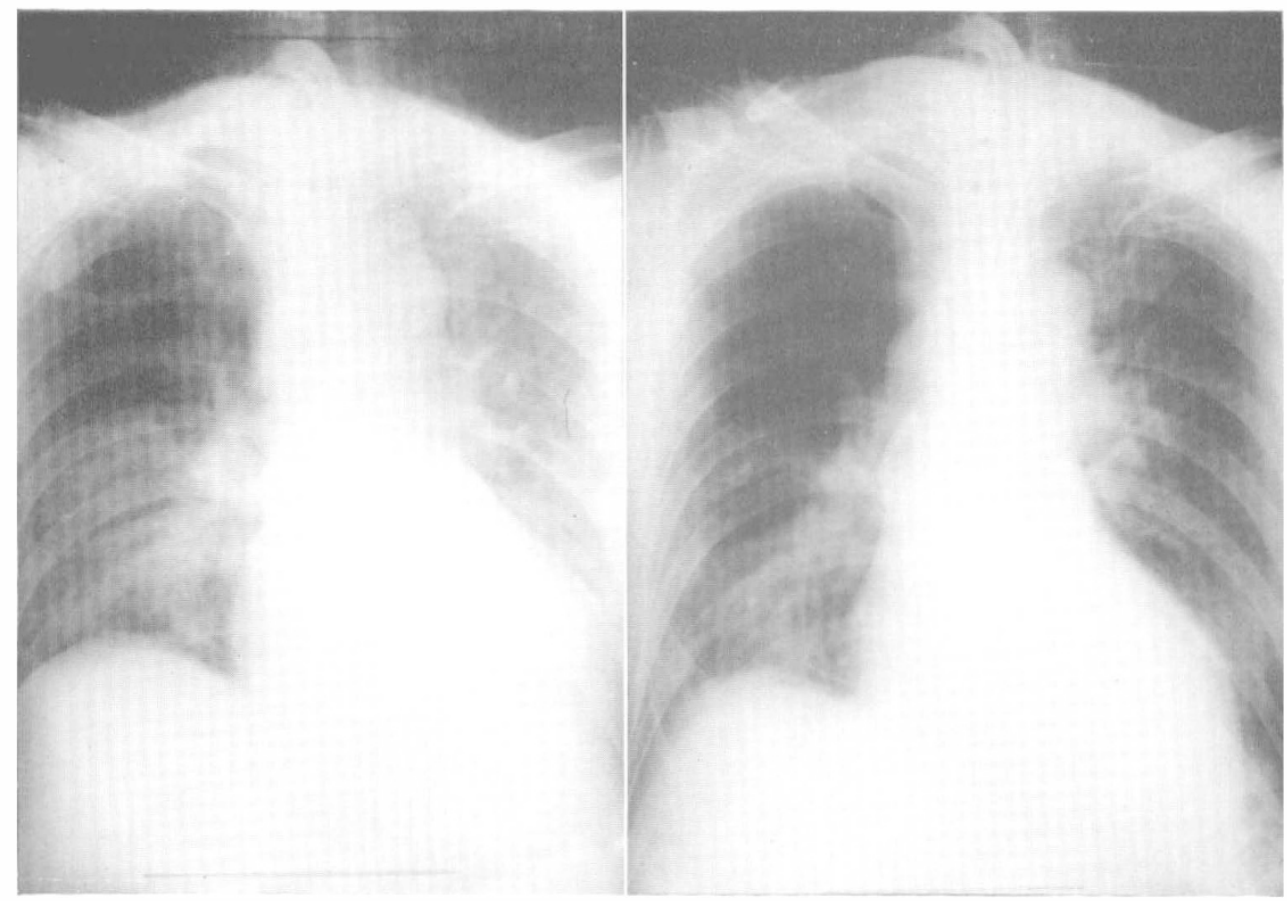

FIG. 2

Chest radiograph taken immediately before bronchial aspiration, showing collapse of the left lower lobe.
FIG. 3

Chest radiograph taken immediately after bronchial aspiration, showing reexpansion of the left lower lobe.

neck from the position of election for the treatment of a cervical fracture or dislocation.

The efficiency of the method has been confirmed both clinically and by taking radiographs to show that the catheter does actually enter the appropriate bronchus. The method is minimally disturbing to the patient-certainly less disturbing than bronchoscopy-and it is also considered that the dangers of trauma to the bronchial mucosa due to repeated aspiration are less than when a rigid bronchoscope is used.

The same rigorous precautions against either trauma or the introduction of infection are necessary with both bronchoscopic and tube aspiration. The details of the techniques used to minimise infection, mucosal trauma, and dehydration of the sputum have been described previously (Cheshire, I964).

It may be argued that it is preferable to perform bronchial aspiration under direct vision, and this may be so the first time. However, if the patient's condition demands frequent aspirations an equally good case may be made for using the technique which is least disturbing to the patient and to his neck, and which is less traumatic to the tracheal and bronchial mucosa.

Tube aspiration is of greatest value in aspirating the main bronchi and in the treatment of lower lobe collapse. In the treatment of upper lobe collapse, bronchoscopic aspiration may be unavoidable. 


\section{SUMMARY}

A technique for aspirating the bronchi of a patient with a tracheostomy is described. Modified Magill's endotracheal tubes are used to serve as a guide for a soft rubber catheter with a single terminal opening.

The efficacy of the method in the prevention and treatment of pulmonary collapse is illustrated.

The method is particularly applicable in the treatment of the acute tetraplegic patient in whom movement of the head and neck are prohibited.

\section{RESUMÉ}

Une technique en vue de l'aspiration des secretions bronchiques chez un malade trachéotomisé est décrite. Des tubes endo-tracheaux du type "Magill", modifiés, sont utilisés afin de guider des sondes en caoutchouc porteurs d'un seul orifice terminal.

L'éfficacité de la méthode dans la prévention et le traitement du collapsus respiratoire est démontrée.

Cette méthode est particulièrement indiquée dans le traitement du tétraplégique dans la phase aigüe chez qui les mouvements de la tête et du cou sont contreindiqués.

\section{ZUSAMMENFASSUNG}

Eine Technik für das Ansaugen der Bronchien eines Patienten mit Tracheostomie wird beschrieben. Modifizierte Schläuche nach Magill werden benutzt, um als Leitung für einen weichen Gummikatheter mit einer terminalen öffnung zu dienen.

Die Wirksamkeit dieser Methode zur Vorbeugung und Behandlung des Lungenkollapses wird illustriert.

Die Methode eignet sich besonders für die Behandlung des Tetraplegikers, bei dem Bewegungen des Kopfes und Halses vermieden werden müssen.

\section{REFERENCE}

Cheshire, D. J. E. (1964). Int. F. Paraplegia, I, 252. 